\title{
Indentation Hardness Measurements at Macro-, Micro-, and Nanoscale: A Critical Overview
}

\author{
Esteban Broitman ${ }^{1}(D)$
}

Received: 25 September 2016/Accepted: 15 December 2016/Published online: 28 December 2016

(C) The Author(s) 2016. This article is published with open access at Springerlink.com

\begin{abstract}
The Brinell, Vickers, Meyer, Rockwell, Shore, IHRD, Knoop, Buchholz, and nanoindentation methods used to measure the indentation hardness of materials at different scales are compared, and main issues and misconceptions in the understanding of these methods are comprehensively reviewed and discussed. Basic equations and parameters employed to calculate hardness are clearly explained, and the different international standards for each method are summarized. The limits for each scale are explored, and the different forms to calculate hardness in each method are compared and established. The influence of elasticity and plasticity of the material in each measurement method is reviewed, and the impact of the surface deformation around the indenter on hardness values is examined. The difficulties for practical conversions of hardness values measured by different methods are explained. Finally, main issues in the hardness interpretation at different scales are carefully discussed, like the influence of grain size in polycrystalline materials, indentation size effects at micro- and nanoscale, and the effect of the substrate when calculating thin films hardness. The paper improves the understanding of what hardness means and what hardness measurements imply at different scales.
\end{abstract}

Keywords Indentation hardness - Macroindentation · Micro-indentation - Nanoindentation - Martens hardness · Hardness Scales

Esteban Broitman

ebroitm@hotmail.com

1 IFM, Linköping University, Linköping SE 58183, Sweden

\section{Introduction}

The hardness of a solid material can be defined as a measure of its resistance to a permanent shape change when a constant compressive force is applied. The deformation can be produced by different mechanisms, like indentation, scratching, cutting, mechanical wear, or bending. In metals, ceramics, and most of polymers, the hardness is related to the plastic deformation of the surface. Hardness has also a close relation to other mechanical properties like strength, ductility, and fatigue resistance, and therefore, hardness testing can be used in the industry as a simple, fast, and relatively cheap material quality control method.

Since the Austrian mineralogist Friedrich Mohs devised in 1812 the first methodical test to measure the hardness [1], a large variety of methods have been established for determining the hardness of a substance. The first report of a machine to measure indentation hardness was done by William Wade in 1856 [2], where a specified load was applied to a pyramid-shaped hardened tool, and the hardness value was evaluated from the size of the deformed cavity on the surface. At the beginning of the twentieth century, there were already commercially available machines for measuring indentation hardness because of the increasing demand for testing steels and rubbers. Mass production of parts in the new aeronautic, automotive, and machine tool industries required every item produced to be quality tested. During World War I and World War II, macroindentation and later micro-indentation tests had a big role for controlling gun production. However, it was only in 1951 when the scientific basis for the indentation hardness tests was settled in the seminal work of Tabor [3]. It represented a revolutionary model based on theoretical developments and careful experiments which provided the physical insight for the understanding of the indentation phenomena [4]. 
The arrival of the microelectronics and nanotechnology age pushed in the 1980s the development of novel methods for the measurement of hardness at nanoscale size [5]. This development was possible thanks to advances in highsensitive instrumentation controlling distances in tens of picometers, and loads below the micro-Newtons range. This novel approach for indentation hardness is based on controlling and recording continuously the indenter position and load during the indentation. The measurement instruments, known as nanoindenters, have very sharp and small tips for the indentation of volumes at the nanoscale.

Nowadays it is known that material hardness is a multifunctional physical property depending on a large number of internal and external factors. The transition from macroscale to microscale and from microscale to nanoscale indentation hardness measurement is accompanied by a decreasing influence of some of these factors and by an increasing contribution of others [6]. Indentation hardness value also depends on the test used to measure it. In order to work with comparable measured values, international standard methods have been developed for different methods at macro-, micro-, and nanoscale [7, 8].

During the last 15 years, the indentation hardness methods have been discussed in many specialized books and papers. A survey for the period 2001-2015 in the database Google Books using as keyword "indentation hardness" estimates 88 books or book chapters, and the same search in Google Scholar gives about 12,100 papers. However, if the same search is done including the names of the main indentation hardness methods discussed in this review (Brinell, Vickers, Meyer, Rockwell, Shore, IHRD, Knoop, and nanoindentation), the search result indicates that only one book [9] but no papers containing all these methods have been published in the period 2001-2015. The book is, in fact, an edited book by Herrmann [9] published in 2011 where all these methods are developed in unconnected chapters written by different authors, so no real correlation of comparison between methods at different scales is developed in the work.

In this paper, the major methods used to measure the indentation hardness of materials at different scales are compared, and main issues and misconceptions in the understanding of these methods are compressively reviewed and discussed. The indentation hardness methods at macro-, micro-, and nanoscale are examined in Sects. 2, 3 , and 4, respectively. The basic equations and parameters employed to calculate hardness are clearly explained, and the different international standards for each method are summarized. Section 5 critically discusses different issues related to indentation hardness at multiple scales. First, the limits for each scale are explored, and the different forms to calculate hardness in each method are compared and established. The influence of elasticity and plasticity of the material in each measurement method is reviewed, and the impact of the surface deformation around the indenter on hardness values is examined. The difficulties for practical conversions of hardness values measured by different methods are explained. Finally, main issues in the hardness interpretation at different scales are carefully discussed, like the influence of grain size in polycrystalline materials, indentation size effects at micro- and nanoscale, and the effect of the substrate when calculating thin films hardness.

\section{Macroindentation Tests}

Macroindentation tests are characterized by indentations loads $L$ in the range of $2 \mathrm{~N}<L<30 \mathrm{kN}$ [10]. The main macroscale tests used by the industry and research communities are: Brinell, Meyer, Vickers, Rockwell, Shore Durometer, and the International Rubber Hardness Degree. These hardness tests determine the materials resistance to the penetration of a non-deformable indenter with a shape of a ball, pyramid, or cone. The hardness is correlated with the plastic deformation of the surface or the penetration depth of the indenter, under a given load, and within a specific period of time.

\subsection{Brinell Test}

Proposed by Johan A. Brinell in 1900, this is from the historic point of view the first standardized indentation hardness test devised for engineering and metallurgy applications [11]. In this test, a ball of diameter $D(\mathrm{~mm})$ is used to indent the material through the application of a load $L$, as shown in Fig. 1. The diameter $d(\mathrm{~mm})$ of the indentation deformation on the surface is measured with an optical microscope, and the Brinell hardness number (BHN) is then calculated as the load divided by the actual area $A_{\mathrm{c}}$ of the curved surface of the impression:

$\mathrm{BHN}=\frac{L}{A_{\mathrm{c}}}=\frac{2 L}{\pi D\left(D-\sqrt{D^{2}-d^{2}}\right)}$

In the original test proposed by Brinell, the load $L$ is expressed in kilogram force. If $L$ is measured in N (SI system), Eq. 1 should be divided by 9.8065 . The full test load is applied for a period of 10-15 s. Two diameters of impression at right angles are measured (usually in the range $2-6 \mathrm{~mm}$ ), and the mean diameter value is used for calculating the Brinell hardness number. The standard from the American Society for Testing and Materials (ASTM) E10-15a [12] and the International Organization for Standardization (ISO) standard 6506-1 [13] explain the standard method for Brinell hardness of metallic materials, as well as the calibration of the testing machine and reference 


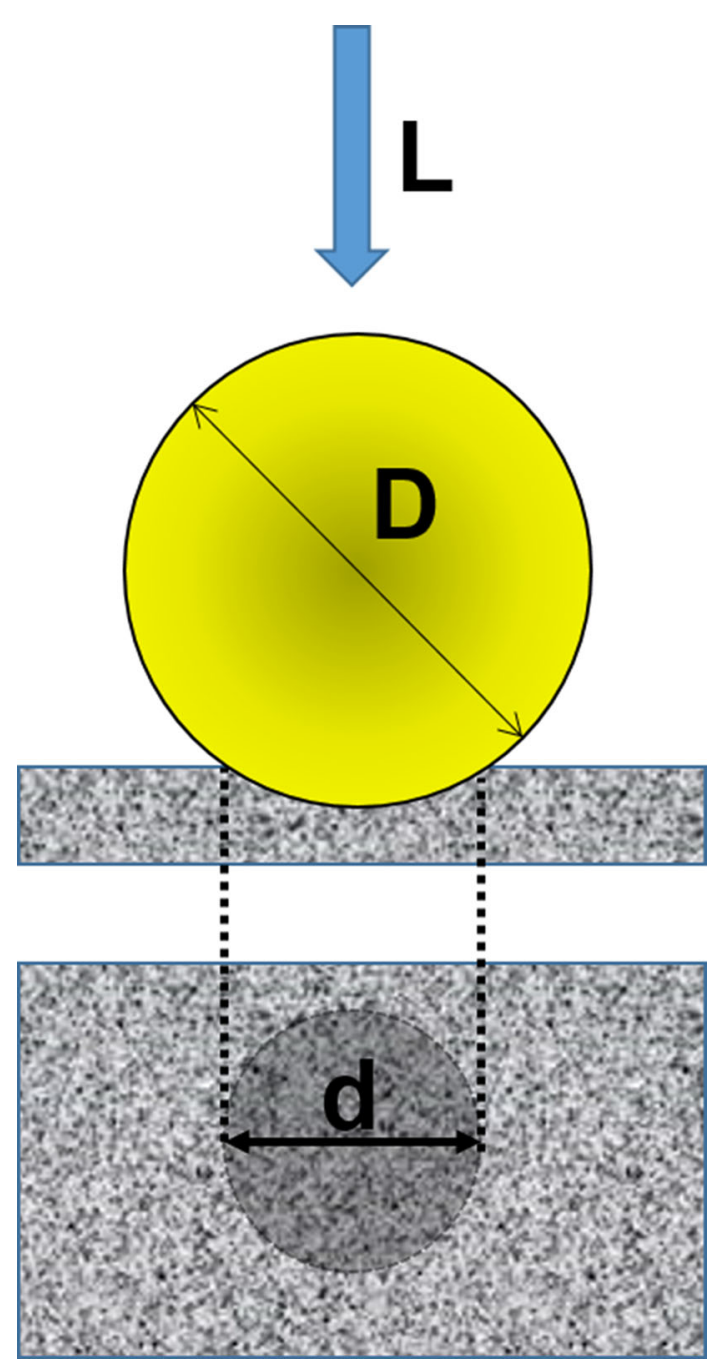

Fig. 1 Brinell macroindentation test

materials. The typical test uses a 10 -mm (0.39 in)-diameter steel ball as an indenter with a $3000 \mathrm{kgf}(\sim 29.4 \mathrm{kN})$ load. For softer materials, a smaller force can be used: $1500 \mathrm{kgf}$ $(\sim 14.7 \mathrm{~N})$ load is usually used for $\mathrm{Al}$, while $\mathrm{Cu}$ is tested using a $500 \mathrm{~kg}(\sim 4.9 \mathrm{kN})$ test force. For harder materials, a tungsten carbide ball substitutes the steel ball. In the European ISO standards, Brinell testing is done using a much wider range of forces and ball sizes: it is common to perform Brinell tests on small parts using a 1-mm carbide ball and a test force as low as $1 \mathrm{~kg}(\sim 9.8 \mathrm{~N})$, referred as "baby" Brinell test [7].

When quoting a Brinell hardness number (BHN or more commonly $\mathrm{HB}$ ), it is also necessary to mention the conditions of the test. There is a standard format for specifying tests: for instance, a value reported as " 125 HB 10/1500/ 30 " means that a Brinell hardness of 125 was obtained using a 10-mm-diameter ball with a $1500 \mathrm{~kg}$ load $(\sim 14.7 \mathrm{kN})$ applied during $30 \mathrm{~s}$.
It is interesting to note that for steels, the hardness $\mathrm{HB}$ value divided by two gives approximately the ultimate tensile strength in units of kilo-pound per square inch $(1 \mathrm{ksi}=\sim 6.9 \mathrm{MPa})$. This feature contributed to its adoption over competing hardness tests in the steel industry.

\subsection{Meyer Test}

Devised by Prof. Eugene Meyer in Germany in 1908, the test is based on the same Brinell test principle (Fig. 1), but the Meyer hardness number (MHN) is expressed as the indentation load $L$ divided by the projected area $A_{\mathrm{p}}$ of the indentation [14],

$\mathrm{MHN}=\frac{L}{A_{\mathrm{p}}}=\frac{4 L}{\pi d^{2}}$

An advantage of the Meyer test is that it is less sensitive to the applied load, especially compared to the Brinell hardness test. Meyer also deduced from ball indentation experiments an empirical relation between the load $L$ and the size $d$ of the indentation in metals, which is known as the Meyer's law,

$L=k d^{n}$

where $k$ is a constant of proportionality. The exponent $n$, known as the Meyer index, was found to depend on the state of work hardening of the metal and to be independent of the size $D$ of the indenting ball. The value of $n$ usually lies between 2 for fully strain hardened materials and 2.5 for fully annealed materials [15].

\subsection{Vickers Test}

The Vickers hardness test is calculated from the size of an impression produced under load by a pyramid-shaped diamond indenter. Devised in the 1920 s by engineers at Vickers, Ltd. (UK) [16], the indenter is a square-based pyramid whose opposite sides meet at the apex with an angle of $136^{\circ}$, the edges at $148^{\circ}$, and faces at $68^{\circ}$. In designing the new indenter, they chose a geometry that would produce hardness numbers nearly identical to Brinell numbers within the range of both tests. The Vickers diamond hardness number, $\mathrm{HV}$, is calculated using the indenter load $L$ and the actual surface area of the impression $A_{\mathrm{c}}$ :

$\mathrm{HV}=\frac{L}{A_{\mathrm{c}}}=\frac{2 L}{d^{2}} \sin \frac{136^{\circ}}{2}=1.8544 \frac{L}{d^{2}}$

where $L$ is measured in $\mathrm{kgf}$ and $d(\mathrm{~mm})$ is equal to the length of the diagonal measured from corner to corner on the residual impression in the specimen surface (Fig. 2). If 
the load is measured in $\mathrm{N}$, Eq. 2 should be divided by 9.8065

The time for the initial application of the force is $2-8 \mathrm{~s}$, and the test force is maintained during 10-15 s. The applied loads vary from 1 to $120 \mathrm{kgf}(\sim 9.8 \mathrm{~N}-1.2 \mathrm{kN})$, with standard values of $5,10,20,30,50,100$, and $120 \mathrm{kgf}(1 \mathrm{kgf}-$ $9.8 \mathrm{~N})[17,18]$. The size of the impression (usually no more than $0.5 \mathrm{~mm}$ ) is measured with the aid of a calibrated microscope with a tolerance of $\pm 1 / 1000 \mathrm{~mm}$. The Vickers hardness can be related to the diagonal $d$ or the penetration depth $\mathrm{t}$ which are related as $d=7 t$. The Vickers contact area and the penetration depth are related as $A_{\mathrm{c}}=24.5 t^{2}$ if the elastic recovery of the material is not important.

The Vickers hardness is denoted as HV, and frequently, the units are also reported as $\mathrm{kgf} / \mathrm{mm}^{2}$, or in $\mathrm{MPa}$ (the value in $\mathrm{kgf} / \mathrm{mm}^{2}$ multiplied by 9.8065$)$.

\subsection{Rockwell Test}

The Rockwell test determines the hardness by measuring the depth of penetration of an indenter under a large load

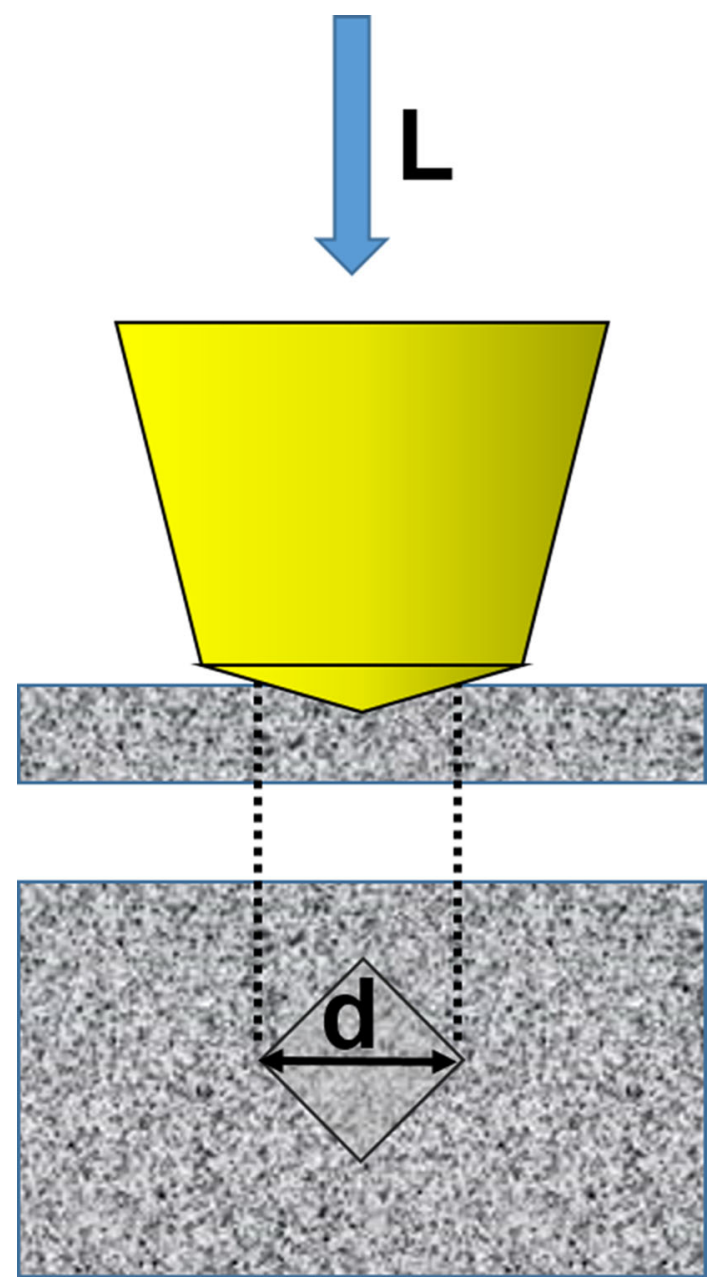

Fig. 2 Vickers micro-indentation test compared to the penetration made by a smaller preload. The differential-depth hardness measurement used in the method was conceived in 1908 by the Austrian professor Paul Ludwik in his book Die Kegelprobe ("the cone test") [19]. The use of an initial low load in this method has the advantage to eliminate errors in measuring the penetration depth, like backlash and surface imperfections. Based on this method, the brothers Hugh M. Rockwell and Stanley P. Rockwell from USA patented a "Rockwell hardness tester," which was a differential-depth machine [20].

The determination of the Rockwell hardness of a material involves the application of a minor load $L_{0}$ of 10 kgf ( $\sim 98.1 \mathrm{~N}$ ) followed by a major load $L_{1}$ (Fig. 3 ). The minor load establishes the zero position. The major load is applied and then removed while still maintaining the minor load. The Rockwell hardness HR is calculated from the equation:

$\mathrm{HR}=N-500 h$

where $h$ (in $\mathrm{mm}$ ) is the difference of the two penetration depth measurements. The value of $\mathrm{N}$ depends on the used indenter: 100 for spheroconical indenters and 130 for a ball. Equation (5) establishes that the penetration depth and hardness are inversely proportional. In this test, no calculations are necessary, as the HR value is read directly from a dial in the machine.

The main advantage of Rockwell hardness is its ability to display hardness values directly, thus obviating tedious calculations involved in other hardness measurement techniques.

There are several $L_{1}$ loads: 60,100 , and $150 \mathrm{kgf}$ ( $1 \mathrm{kgf}-$ $9.8 \mathrm{~N}$ ), and several ball diameters: $1 / 2,1 / 4,1 / 8$, and 1/16 inch $(1$ inch-2.52 cm) that can be used, as established in the standards ISO 6508-1 [21] and ASTM E18 [22] for metallic materials, and ISO 2039-2 [23] for plastics. These methods are named with letters: (scales A, B, C, D, E, F, G, $\mathrm{H}, \mathrm{K}, \mathrm{L}, \mathrm{M}, \mathrm{P}, \mathrm{R}, \mathrm{S}$, and V), and the most used ones are explained in Table 1. The correct notation for a Rockwell hardness value is HR followed by the scale (e.g., $62 \mathrm{HRC}$ ) where $\mathrm{C}$ is the letter for the scale used.

The spheroconical indenter used in some of the scales (also known as Brale indenter) is made with a diamond of $120^{\circ} \pm 0.35^{\circ}$ included angle. The tip of the diamond is spherical with a mean radius of $0.200 \pm 0.010 \mathrm{~mm}$, as shown in Fig. 4.

There is also a superficial Rockwell hardness scale, where the initial test force $\mathrm{L}_{0}$ is $3 \mathrm{kgf}(\sim 29.4 \mathrm{~N})$, and the final test forces $\mathrm{L}_{1}$ applied during testing are also lower: 15,30 , and $45 \mathrm{kgf}(1 \mathrm{kgf}=9.8065 \mathrm{~N})$. These lower test forces involve a lower penetration depth scale, being used on brittle and very thin materials. The superficial Rockwell hardness HR is calculated from the equation: 

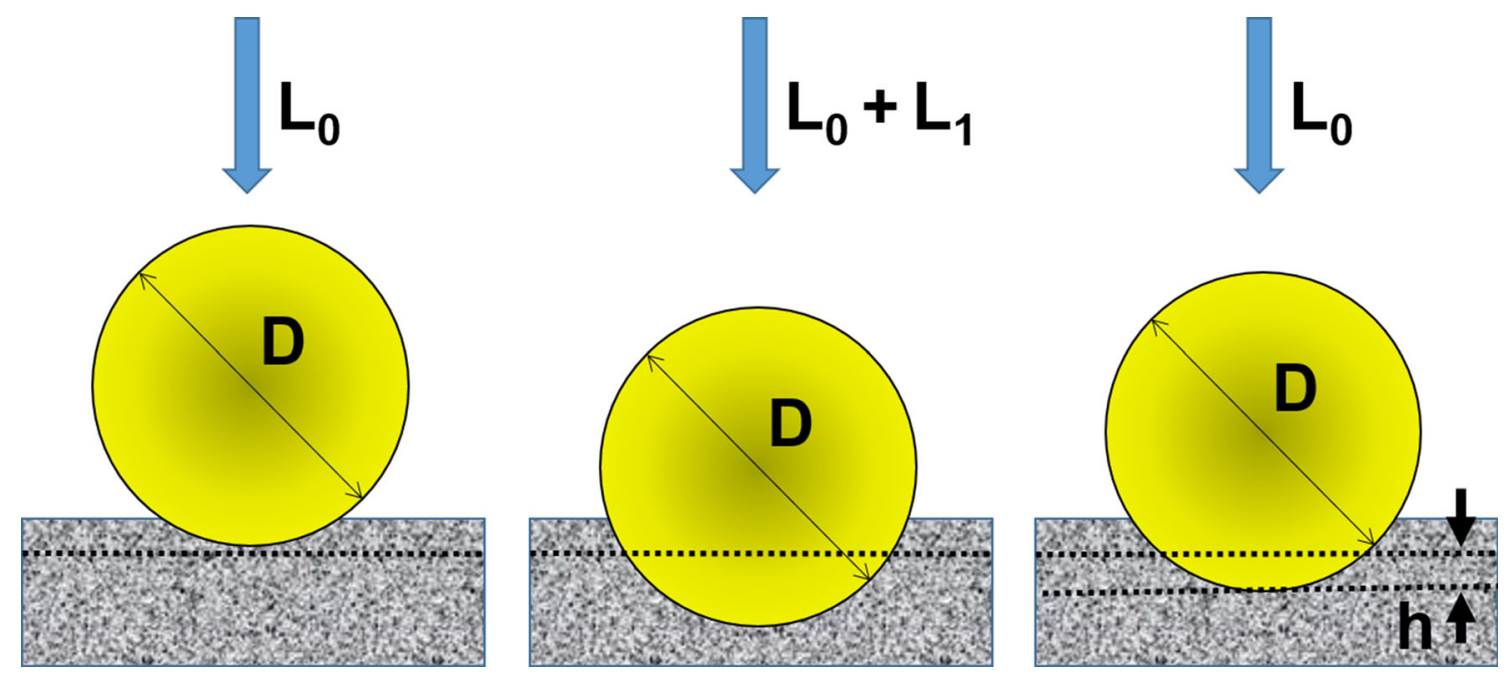

Fig. 3 Principle of the macroindentation Rockwell test. The indenter can be a sphere or a cone

Table 1 Main Rockwell scales

\begin{tabular}{lllr}
\hline Scale & Name & Indenter & Load $(\mathrm{kgf})$ \\
\hline A & HRA & $120^{\circ}$ diamond spheroconical & 60 \\
B & HRB & $1 / 16$-inch-diameter $(1.588 \mathrm{~mm})$ steel sphere & 100 \\
C & HRC & $120^{\circ}$ diamond spheroconical & 150 \\
D & HRD & $120^{\circ}$ diamond spheroconical & 100 \\
E & HRE & $1 / 8$-inch-diameter $(3.175 \mathrm{~mm})$ steel sphere & 100 \\
F & HRF & $1 / 16$-inch-diameter $(1.588 \mathrm{~mm})$ steel sphere & 60 \\
G & HRG & $1 / 16$-inch-diameter $(1.588 \mathrm{~mm})$ steel sphere & 150 \\
\hline
\end{tabular}

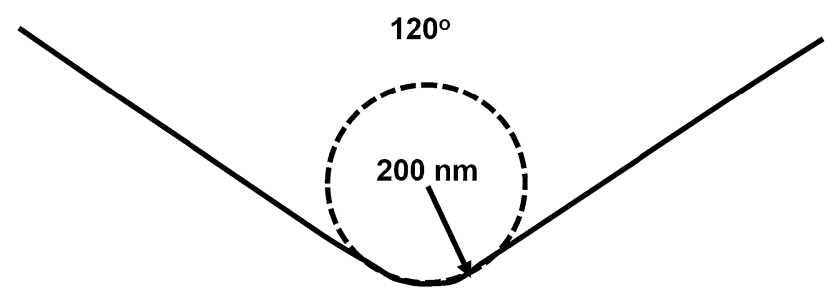

Fig. 4 Spheroconical diamond indenter used in some Rockwell tests

Superficial HR $=100-1000 h$

where $h$ (in $\mathrm{mm}$ ) is also the difference of the two penetration depth measurements. The notation in this case is as follows: 30T-25 indicates the superficial hardness as 25 , with a load of 30 kilograms ( $\sim 294.2 \mathrm{~N})$ using a 1/16-inchdiameter steel ball. If the diamond cone were used instead, the " $T$ " would be replaced by an " $N$."

\subsection{Shore Durometer}

The durometer scale was defined by Albert Ferdinand Shore in 1927 when he filed a patent for a device to measure hardness. The device consists of a calibrated spring applying a specific pressure to an indenter foot, which can be either cone or sphere shaped (Fig. 5) [24]. An indicating needle in a dial measures the depth of indentation in a scale from 0 (for full penetration of the indenter) to 100 (corresponding to no penetration of the indenter). The method measures, in fact, the maximum penetration at the applied load and not the deformation of the material. As this method is used to measure viscoelastic materials, it requires to measure also the movement of the indenter

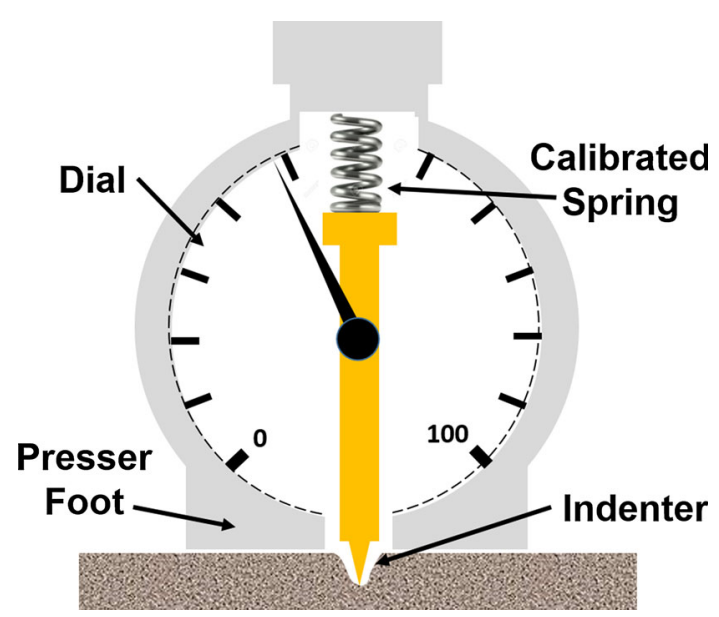

Fig. 5 Basic scheme of a Shore durometer 
during a specific time. The determination of the final durometer hardness is achieved by visually reading the dial within $1 \mathrm{~s}$ of the "moment of cessation" of the numerical increase in the indication, which is generally agreed upon a specific reference time. The introduction of electronics, digital displays, and miniaturization has allowed the construction of durometers using load cells and pressure-force transducers, replacing springs, mechanical dials, and visual guess. Durometers are available in a variety of models, according to the maximum applied $\operatorname{load}(78,113,197,822$, and $4536 \mathrm{gf}$, where $1 \mathrm{gf} \sim 9.8 \mathrm{mN}$ ) and the size and kind of indenter (cone, truncated cone, disc, and sphere) which are normalized within 12 scales by the standard ASTM D2240 [25]. The indenter should be manufactured from hardened steel 500HV10. According also to ASTM D2240, this test method is an empirical test intended primarily for control purposes. No simple relationship exists between indentation hardness determined by this test method and those obtained with another type of durometer or other instruments used for measuring hardness [25]. The shore durometer is used mainly for measuring the indentation hardness of rubbers, thermoplastic elastomers, and soft plastics such as polyolefin, fluoropolymer, and vinyl [26].

The Barber-Colman Impressor, or shortly known as Barcol Impressor, is a handheld portable durometer developed by Walter Colman during World War II to check the hardness of aircraft rivets. Fifty years later, the same Barcol product has been used to perform hardness testing on repairs to the USA Space Shuttle [27]. The governing standard for the Barcol hardness test is ASTM D 2583 [28]. This method is used nowadays to determine the hardness of reinforced and non-reinforced rigid plastics and to determine the degree of cure of resins and plastics.

\subsection{International Rubber Hardness Degree (IRHD)}

This test designed for rubber materials is similar to the differential Rockwell hardness testing: a ball fitting inside an annular foot to hold the sample in place is first under the action of a contact force $L_{0}=0.3 \mathrm{~N}$ with a duration time of $5 \mathrm{~s}$, and the depth-measuring system is reset to zero. Then, an additional constant indenting force of $L_{1}=5.4 \mathrm{~N}$ is applied during $30 \mathrm{~s}$ and the penetration depth $D$ is measured (Fig. 6).

The relation between the difference of penetration $D$ and the IRHD hardness is based on the empirical equation of contact mechanics for a fully elastic isotropic material

$\frac{F}{E}=0.0038 r^{0.65} D^{1.35}$

where $F$ is the indenting force in Newtons, $r$ is the radius of the ball in $\mathrm{mm}$, and $D$ is the indentation depth in $\mathrm{mm}$ [29].
The measured penetration $D$ is converted into IRHD using the value of $E$ obtained from Eq. (7) into the Eq. (8):

$\mathrm{IHRD}=f(E)=\frac{100}{\sigma \sqrt{2 \pi}} \int_{-\infty}^{\log _{10} E} e^{\frac{(t-a)^{2}}{2 \sigma^{2}}} \mathrm{~d} t$

with $a=0.34$ and $\sigma=0.7$. This relation is chosen in a way that IHRD $=0$ represents a material having an elastic modulus $E=0$ and IHRD $=100$ represents a material of infinite elastic modulus.

According to Morgans et al. [30], there are some reports of using the IRHD method in the 1920s, but the first standard was introduced as a British Standard BS in 1940. The modern test procedure in ISO 48 [29] contains three macroscale methods for the determination of the hardness on flat surfaces: normal $(N)$, high $(H)$, and low $(L)$ hardness, and three for curved surfaces ( $\mathrm{CN}, \mathrm{CH}$, and $\mathrm{CL})$. The three methods differ primarily in the diameter of the indenting ball: $2.5,1$, and $5 \mathrm{~mm}$ for $N, H$, and $L$, respectively. There is also a corresponding international ASTM norm D1415 [31].

\section{Micro-indentation Tests}

Micro-indentation tests are characterized by indentations loads $L$ in the range of $L<2 \mathrm{~N}$ and penetrations $h>0.2 \mu \mathrm{m}$ [10]. There are two main tests used at this scale: Vickers and Knoop. These indentation hardness tests determine the material resistance to the penetration of a diamond indenter with a shape of a pyramid. Like in the case of macroindentation tests, the hardness is correlated with the depth which such indenter will sink into the material, under a given load, within a specific period of time.

\subsection{Micro-Vickers Test}

The micro-indentation Vickers test is similar to the macroindentation test explained in Sect. 2.2 The difference is the use of a lower applied load range. The use of forces below $1 \mathrm{kgf}(\sim 9.8 \mathrm{~N})$ with the Vickers test was first evaluated in 1932 at the National Physical Laboratory in the UK [32]. Four years later, Lips and Sack constructed the first micro-hardness Vickers tester designed for applied forces $\leq 1 \mathrm{kgf}(\sim 9.8 \mathrm{~N})$ [33]. The test is normalized by ASTM E384 [34] and ISO 6507 [17].

\subsection{Knoop Test}

Developed in 1939 at the USA National Bureau of Standards (nowadays NIST) by Frederick Knoop, the indenter is a rhombic-based pyramidal diamond that produces an 
Fig. 6 Scheme of the IHRD test

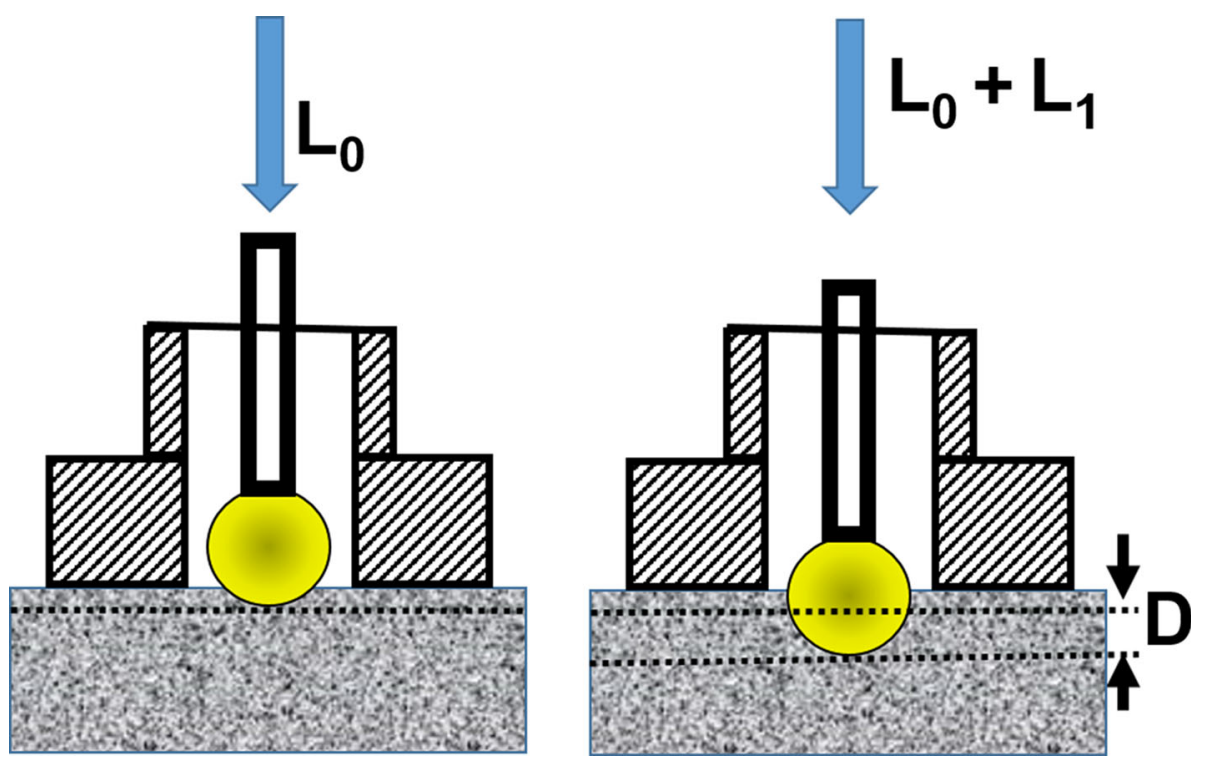

elongated diamond shaped indent: the angles from the opposite faces of the indenter are $130^{\circ}$ and $172.5^{\circ}$ [35]. The Knoop indenter produces a rhombic-shaped indentation having approximate ratio between long and short diagonals of 7 to 1 (Fig. 7).

The Knoop hardness number (KHN) is defined as the ratio of the applied load $L$ divided by the projected area $A_{\mathrm{p}}$ of the indent.

$\mathrm{KHN}=\frac{L}{A_{\mathrm{p}}}=\frac{2 L}{d^{2}\left[\cot \frac{172.5^{\circ}}{2} \tan \frac{130^{\circ}}{2}\right]}=14.24 \frac{L}{d^{2}}$

where $d$ is the length of the longest diagonal (in $\mathrm{mm}$ ). $L$ was originally measured in $\mathrm{kgf}$; if $L$ is measured in $N$, Eq. 2 should be divided by 9.8065 . The process measurement consists in pressing the indenter by a load which is maintained by $10-15 \mathrm{~s}$. After the dwell time is complete, the indenter is removed leaving an elongated diamond shaped indent in the sample. Knoop tests are mainly done at test forces from 10 to $1000 \mathrm{~g} \mathrm{(} 98 \mathrm{mN}$ to $9.8 \mathrm{~N})$, so a high-magnification microscope is necessary to measure the indent size [18, 34].

\subsection{Buchholz Test}

This test method was developed originally to analyze the indentation hardness of paints with plastic deformation behavior. The indenter is a sharp doubly beveled disk indenting tool made in steel, as shown in Fig. 8. The indentation procedure consists on applying a $500 \mathrm{gf}$ load $L(\sim 4.9 \mathrm{~N})$ during 30 , and $35 \mathrm{~s}$ later the indentation length $\mathrm{d}(\mathrm{mm})$ is measured with the help of a precision $20 \times$ magnification microscope. The indentation resistance Buchholz (IRB) is then calculated according to the following equation:
Fig. 7 Comparison of Knoop and Vickers micro-indentations
Knoop

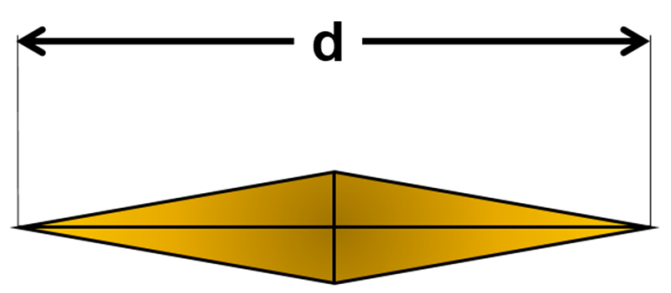

$\mathrm{d}=30.5 \mathrm{~h}$
Vicker

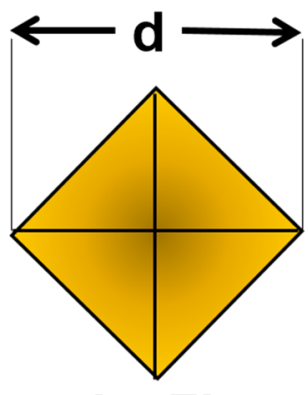

$\mathrm{d}=7 \mathrm{~h}$ 
$\mathrm{IRB}=\frac{100 \mathrm{~mm}}{d}$

The disk dimensions are standardized: diameter of $30 \mathrm{~mm}$, thickness of $5 \mathrm{~mm}$, and $120^{\circ}$ bevel angle. The test is particularly sensitive to the positioning and removal of the apparatus, as well as to the recovery time before measuring the indentation length. The standard ISO 2815 describes the measurement method which is valid for single coating or a multicoating system of paints, varnishes, or related products [36]. The norm also establishes values for the equivalent penetration $\mathrm{h}$ of the indenter, the limits of the indentation mark $0.75<d<1.75$, and the range of film thickness $15 \mu \mathrm{m}<t<35 \mu \mathrm{m}$ where the calculation is valid. Furthermore, the norm specifies that the undisturbed, non-indented film layer below the indentation mark should be at least $10 \mu \mathrm{m}$ thick.

\subsection{Micro-IHRD Test}

The micro-indentation IHRD test is similar to the macroindentation test explained in Sect. 2.6 The difference is the use of a lower load and smaller ball. The test procedure in ISO 48 [29] contains the microscale method M and the corresponding MC for curved surfaces. The method at the microscale uses a ball diameter of $0.395 \mathrm{~mm}$, a contact load. $L_{\mathrm{o}}=0.0083 \mathrm{~N}$, and a total force $L_{\mathrm{o}}+$ $L_{1}=0.1533 \mathrm{~N}$. The test can be used in rubber sheets of at least $2 \mathrm{~mm}$ thick. This test at microscale is very useful because it avoids the trouble and cost of making an extra molding to make a macrosized sample, which might also have a different degree of cure. The method is also useful when the change of hardness is used to measure the effect

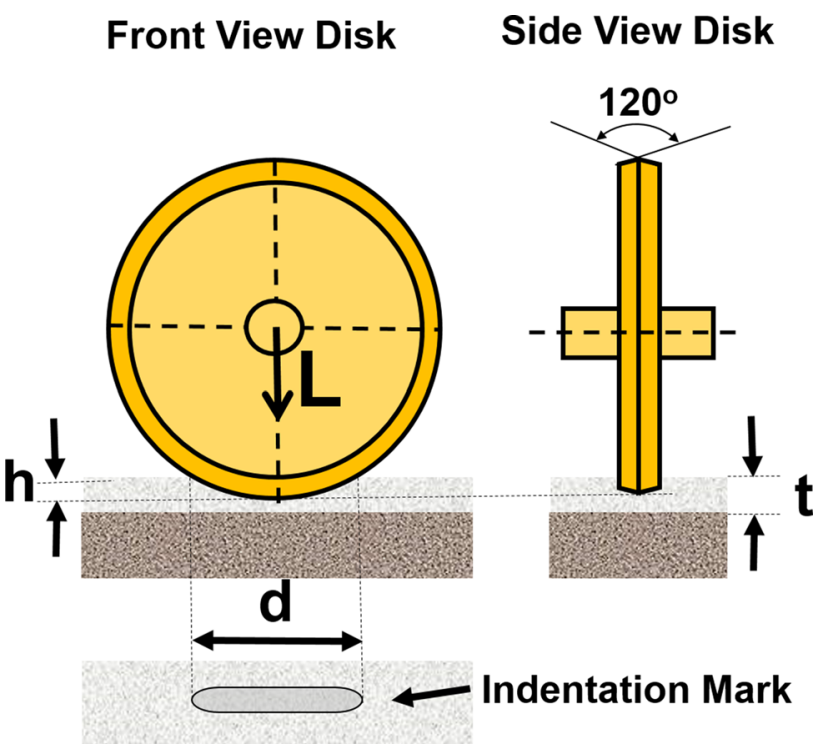

Fig. 8 Schematics of a Buchholz test of aging or weathering, as the restriction on oxygen diffusion would be much less than in a macro test piece. Another possible application is the investigation of cure level as a function of rubber thickness [37].

\section{Nanoindentation Tests}

In the nanoindentation test, the indenter is pushed into the surface of the sample producing both elastic and plastic deformation of the material (Fig. 9). The first difference with macro- or micro-indentation tests is that, in the nanoindentation machines, the displacement $h$ and the load $L$ are continuously monitored with high precision, as schematically shown in Fig. 10. During the nanoindentation process, the indenter will penetrate the sample until a predetermined maximum load $L_{\max }$ is reached, where the corresponding penetration depth is $h_{\max }$. When the indenter is withdrawn from the sample, the unloading displacement is also continuously monitored until the zero load is reached and a final or residual penetration depth $h_{f}$ is measured. The slope of the upper portion of the unloading curve, denoted as $S=\mathrm{d} L / \mathrm{d} h$, is called the elastic contact stiffness.

There are mainly two indenter shapes of choice in nanoindentation: Berkovich and cube corner [5]. The Berkovich indenter is a three-sided pyramid with a face angle of $65.3^{\circ}$ with respect to the indentation vertical axis, and its area-to-depth function is the same as that of a Vickers indenter [38]. The cube corner is also a three-sided pyramid which is precisely the corner of a cube.

In nanoindentation, the hardness of the material is defined as $H=L / A_{\mathrm{pml}}$, where $A_{\mathrm{pml}}$ is the projected area of

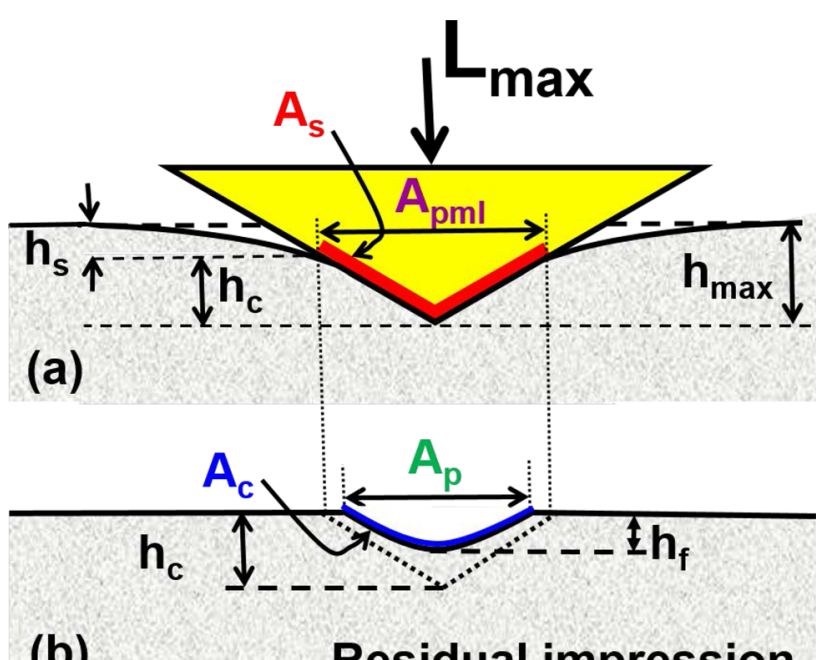

(b)

Residual impression

Fig. 9 a Elasto-plastic deformation at the maximum applied load $L_{\text {max }} ;$ b plastic deformation after releasing the load 


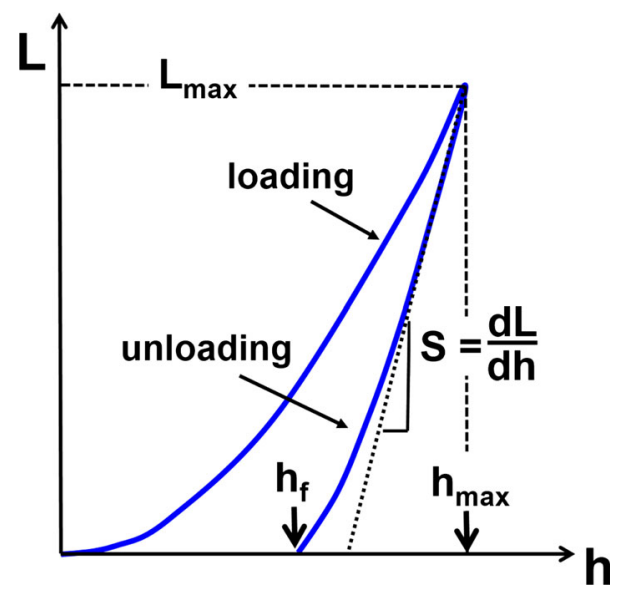

Fig. 10 Load-unload during nanoindentation

contact at the maximum load. In this method, the maximum load ranges between few $\mu \mathrm{N}$ and about $200 \mathrm{mN}$, while penetrations will vary from few $\mathrm{nm}$ to about few $\mu \mathrm{m}$. The indented area results to be very small (nanometer or few micrometers size), and as a consequence, the use of optical microscopy is not possible like in macro- and micro-indentation tests. The only way for observing so small areas is by using a scanning electron microscopy (SEM), which is not very practical. However, methods have been developed to calculate the area directly from the load-unload curve.

Oliver and Pharr developed in the 1990s a method to accurately calculate $\mathrm{H}$ and $\mathrm{E}$ from the indentation loaddisplacement data, without any need to measure the deformed area with a microscope [39]. The first step in their method consists in fitting the unloading part of the load-displacement data to the power-law relation derived from the elastic contact theory:

$L=\beta\left(h-h_{\mathrm{f}}\right)^{m}$

where $\beta$ and $\mathrm{m}$ are empirically determined fitting parameters and $h_{\mathrm{f}}$ is the final displacement after complete unloading, also determined from the curve fit (Figs. 9, 10) [40]. The second step in the analysis consists of finding the contact stiffness $\mathrm{S}$ by differentiating the unloading curve fit, and evaluating the result at the maximum depth of penetration, $h=h_{\max }$. This gives

$S=\left(\frac{\mathrm{d} L}{\mathrm{~d} h}\right)_{h=h_{\max }}=\beta m\left(h_{\max }-h_{\mathrm{f}}\right)^{m-1}$

The third step in the procedure is to determine the contact depth $h_{c}$ which for an elastic contact is smaller than the total depth of penetration. Assuming that pileup is negligible, an elastic model shows that the amount of sink-in $h_{\mathrm{s}}$ (indicated in Fig. 9a) is given by

$h_{\mathrm{s}}=\varepsilon L_{\max } / S$ where $\varepsilon$ is a constant that depends on the geometry of the indenter [41]. Based on empirical observation with Berkovich and cube-corner indenters, the value $\varepsilon=0.75$ has become the value used for analysis [41].

The contact depth is estimated according to:

$h_{\mathrm{c}}=h_{\max }-h_{\mathrm{s}}=h_{\max }-\varepsilon L_{\max } / S$

It should be emphasized again that the correction for $h_{\mathrm{c}}$ is not valid in the case of material pileup around an indent. Therefore, inspection of the residual impression using a scanning electron microscope (SEM) or an atomic force microscope (AFM) is useful.

If we assume that we have an ideal Berkovich indenter, the projected area can be calculated as:

$A_{\mathrm{pml}}=3 \sqrt{3} \tan ^{2}(\alpha / 2) h_{\mathrm{c}}^{2}=24.56 h_{\mathrm{c}}^{2}$

where $\alpha=130.6^{\circ}$ is the angle of the Berkovich indenter. In this way, the substitution of $h_{\mathrm{c}}$ from (8) (with the use of the calculated value of $\mathrm{S}$ from the load-displacement curve at $h=h_{\text {max }}$ ) gives a value for $A_{\mathrm{pml}}$ to calculate $H=$ $L_{\max } / A_{\mathrm{pml}}$.

Unfortunately, a perfect Berkovich indenter is a utopia. Even if they are carefully manufactured, the indenter tips are usually blunted and/or can have other defects, or they become imperfect after few nanoindentations. However, the method of Oliver and Pharr also shows how to calculate the projected contact area at maximum load $A_{\mathrm{pml}}$ by evaluating an empirically determined indenter area function $A_{\mathrm{pml}}=f\left(h_{\mathrm{c}}\right)$. The area function $f\left(h_{\mathrm{c}}\right)$ is also called the shape function or tip function because it relates the crosssectional area of the indenter $A_{\mathrm{p}}$ to the distance $h_{\mathrm{c}}$ from its tip. A general polynomial form is used:

$A_{\mathrm{pml}}=f\left(h_{\mathrm{c}}\right)=24.56 h_{\mathrm{c}}^{2}+C_{1} h_{\mathrm{c}}^{1}+C_{2} h_{\mathrm{c}}^{1 / 2}+C_{3} h_{\mathrm{c}}^{1 / 4}+\cdots$

The first term of the polynomial fit corresponds to the ideal Berkovich indenter, and the remaining terms take into consideration the deviations from the ideal geometry.

The fitting parameters $C_{i}$ can be obtained by performing nanoindentation tests on materials with known elastic modulus. The most used material used for the fitting is fused quartz, with a known hardness $H=9.25 \mathrm{GPa}$. Fused quartz material used for calibration has a very smooth surface, is amorphous, and presents no pileup.

The number of terms in Eq. (16) is chosen to give a good fit over the entire range of analyzed depths, using a weighted fitting procedure to assure that data from all depths have equal importance.

One interesting characteristic of the nanoindentation technique is the possibility to calculate not only the hardness, but also the elastic modulus of the material. The calculation can be done using the fundamental relation 
$S=\frac{2}{B \sqrt{\pi}} E_{\mathrm{r}} \sqrt{A_{\mathrm{pml}}}$

where $B$ is a geometrical factor depending on the indenter [41]. $E_{\mathrm{r}}$ is the reduced elastic modulus of the contact defined as:

$\frac{1}{E_{\mathrm{r}}}=\frac{1-v^{2}}{E}-\frac{1-v_{i}^{2}}{E_{i}}$

with $E$ and $v$ are the elastic modulus and Poisson's ratio of the sample and $E_{i}$ and $v_{i}$ the elastic modulus and Poisson's ratio of the indenter.

Equation (17) is based on the classical problem of the axisymmetric contact of a smooth, rigid, circular punch with an isotropic elastic half-space whose elastic properties $E$ and $v$ are constants. For indenters with triangular cross section such as the Berkovich pyramid, $B=1.034$ [39].

The reduced modulus in Eq. (17) is used to take into consideration that both sample and indenter have elastic deformation during the nanoindentation. For a diamond indenter, the values $E_{i}=1140 \mathrm{GPa}$ and $v_{i}=0.07$ are frequently used. Equation (18) requires to know the Poisson's ratio of the sample which is usually unknown. One possibility is to use a value $v=0.25$ which produces in most materials about a $5 \%$ uncertainty in the calculated value of $E$. Most of publications, however, report the value of the reduced elastic modulus $E_{\mathrm{r}}$ to avoid guessing a value for the Poisson's ratio. The main international standards for nanoindentation are ISO 14577 [10] and ASTM E2546 [42].

Improvements to measurement and calibration procedures have been facilitated in the last decade by the continuous stiffness measurement (CSM) technique, in which the stiffness is measured continuously during the loading of the indenter by imposing a small oscillation on the force (or displacement) signal and measuring the amplitude and phase of the corresponding displacement (or force) signal by means of a frequency-specific amplifier [40]. New advances in nanoindentation hardware have also allowed the possibility to make nowadays in situ experiments in a wide range of temperatures of up to $700{ }^{\circ} \mathrm{C}$ [43], to characterize small features as standing alone nanowires and nanorods [44, 45], or to adapt nanoindenters to measure piezoelectricity at the nanoscale [46].

\section{Tests Comparison}

\subsection{The Scales of Hardness Indentation Tests}

While in the field of tribology the limits of macro-, micro-, and nanoscale experiments are still blurry [47], there is some consensus in the indentation mechanics area about which tests can be considered to belong to each scale. Brinell and Rockwell tests are considered to be in the macroscale, due to the high loads $(5 \mathrm{~N}-30 \mathrm{kN})$, high deformation areas, and high penetrations (more than $1 \mathrm{~mm}$ ). Vickers and IHRD are considered to be a macro- or microscale, according to the applied load. Knoop test is considered to be a microscale test, with low loads and low penetration depths (up to $0.1 \mathrm{~mm}$ ). Buchholz is also a microscale test because of the low penetration depth into the coatings $(15-35 \mu \mathrm{m})$. Finally, indentations made with nanoindenters or atomic force microscopes are considered as nanoscale tests, with loads $L<30 \mathrm{mN}$ and penetrations $<5 \mu \mathrm{m}$. The limits in the scales are not very clear for all methods. The "baby" Brinell cannot be considered a microscale test because the penetration is usually high, and the Rockwell test $T$, done for thin materials, lies in the limit between macro- and microscale.

There is also some disagreement in the standards regarding the load range applicable to microscale testing. ASTM Specification E384, for example, states that the load range for microscale testing is $1-1000 \mathrm{gf}(\sim 9.8 \mathrm{mN}$ to $\sim 9.8 \mathrm{~N}$ ) [34]. On the other hand, the ISO 14577-1 norm specifies that the microscale indentation is for loads lower than $200 \mathrm{gf}(\sim 1.96 \mathrm{~N})$. In fact, this ISO norm gives the ranges of loads and penetrations for determining the indentation hardness at the three scale definitions [10], as shown in Table 2.

Figure 11 shows an estimation of the number of scientific publications dealing with indentation hardness of materials in the period of years going from 1910 to 2015 . Each indicated year data in the figure include all publications in the precedent period of 15 years. The survey separates the publications according to the macro-, micro-, or nanoscale where the indentation hardness has been measured. The estimation was done with the database from Google Scholar, using as keywords: "indentation hardness," "micro-indentation," and "nanoindentation," through a Boolean logic search to exclude publications dealing simultaneously with two or three scale measurements in the same publication. It is observed a huge increase trend of publications in the nanoscale area during the last 15 years, surpassing the number of publications at microscale.

Table 2 Hardness testing scales defined by ISO 14577-1 [1]

\begin{tabular}{lll}
\hline & Load range $(\mathrm{N})$ & Penetration range $(\mu \mathrm{m})$ \\
\hline Macroscale & $2<L<30,000$ & Not specified \\
Microscale & $L<2$ & $h>0.2$ \\
Nanoscale & Not specified & $h<0.2$ \\
\hline
\end{tabular}




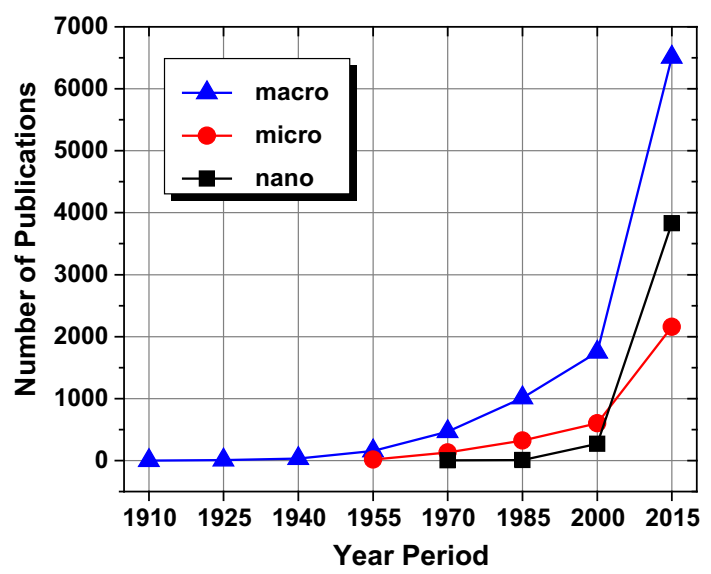

Fig. 11 Number of publications reporting results of indentation hardness at macro- (filled triangle), micro- (filled circle), and nanoscale (filled square). The estimation was done using the database Google Scholar. Each data point reports number of publications in the previous 5-year period

\subsection{Indentation Hardness Definitions}

The indentation hardness in the aforementioned methods is defined in three different ways. Brinell and Vickers define hardness as the applied load $L$ divided by the actual area $A_{\mathrm{c}}$ of the impressed curved surface. Meyer, Knoop, and the nanoindentation hardness are defined as the ratio of the applied load $L$ to the projected areas $\left(A_{\mathrm{p}}\right.$ or $\left.A_{\mathrm{pml}}\right)$ of the indent. Finally, the Rockwell, Shore, IHRD, and Buchholz tests determine the hardness by measuring the depth of penetration of an indenter under a large load.

There are some authors who explain that there is just a geometrical difference between the actual area $A_{\mathrm{c}}$ of the curved surface of the impression and the projected area $A_{\mathrm{p}}$ of the indent. However, this geometrical approximation is valid if the indentation produces a $100 \%$ plastic deformation. If the material has an elastic-plastic behavior, the geometrical conversion between methods is difficult [48].

In the case of projected areas, in Knoop indentation $A_{\mathrm{p}}$ is measured after the elastic recovery took place, while in nanoindentation the area $A_{\mathrm{pml}}$ is calculated at the time of the maximum applied load, so both areas will differ according to the amount of elastic recovery of the material.

Finally, in the Rockwell, Shore Durometer, Buchholz, and IHRD methods, the indentation depth is measured to calculate the hardness, and the final deformed area is very difficult to relate to the projected or actual deformed areas of the other indentation tests.

It is well known that solids have three responses to an applied force, which depends on the force strength and material. Figure 12 shows the scheme of a typical stressstrain curve, where three regions can be observed:
- Elastic the material changes temporarily its shape, but returns to the original shape when the stress is removed. Deformation in the elastic region is linear, as described by the stress-strain curve. In this region, the definition of indentation hardness as the ratio of applied load divided by the permanent deformed area is not applicable. Penetration methods to measure hardness, like the Shore durometer, IHRD, or Buchholz tests, must be used to measure meaningful hardness values.

- Plastic the material has a permanent change shape in response to the stress, but remains in one piece. The yield strength is the point at which elastic deformation gives way to plastic deformation. Deformation in the plastic region is nonlinear, as described by the stressstrain curve. Indentation hardness measurements in this region can be done using permanent deformation areas or indenter penetration, as described above.

- Fracture the material cracks and separates into two or more pieces. The fracture property in indentation methods can be used to calculate other mechanical properties like indentation toughness [49].

When the material is indented, there will be elastic and plastic deformations according to the applied level of stress. All macro- and micro-indentation tests using $A_{\mathrm{c}}$ or $A_{\mathrm{p}}$ measure the plastic deformed area after the material has recuperated elastically. The calculation of hardness can give different values by different methods, even applying the geometrical correction. The difference will depend on how much the applied stresses in each method will deform the material into the elastic and plastic zones, giving place to more or less elastic recovery. Furthermore, behaviors of sink-in or pileup around the indented area are usually neglected, even if they were already studied in the early development of the methods. Norbury et al. [50] published a pioneering study of the piling-up and sinking-in during Brinell indentation hardness tests where they found a large effect on hardness measurement. Of course, these differences could fall inside the measurement error if the

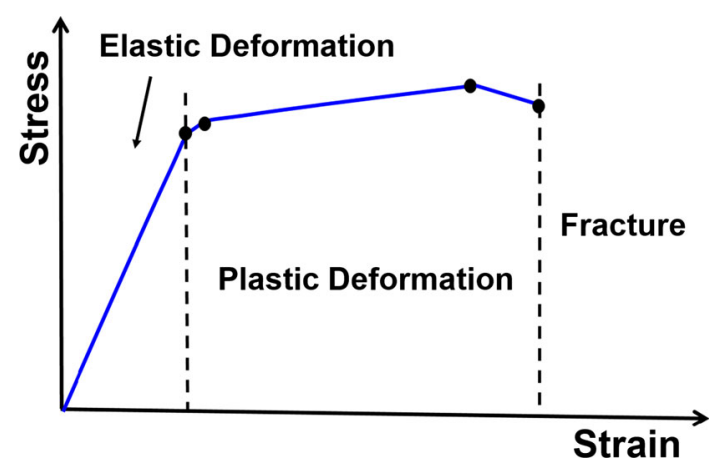

Fig. 12 Scheme of a typical stress-strain curve 
deformed areas are measured with microscopes of low magnification.

The case is different for nanoindentation. First, the contact area $A_{\mathrm{pml}}$ is calculated, and not directly measured. The calculation of $A_{\mathrm{pml}}$ developed by Oliver and Pharr is, however, only valid for materials where the surface around the indenter sinks in, as shown in Figs. 6 and 9a. If the opposite indentation deformation phenomenon of "pileup" occurs (i.e., the surface of the sample around the indenter is at a higher level than its surroundings as shown in Fig. 13b), the predicted contact area is smaller than the real one. Therefore, the contact area supporting the indenter at $L=L_{\max }$ increases and the measured elastic modulus and hardness can be significantly overestimated up to $50 \%$ [40].

Oliver and Pharr have shown that the amount of pileup or sink-in depends on $h_{\mathrm{f}} / h_{\max }$ and the work-hardening behavior [40]. Specifically, pileup is large only when $h_{\mathrm{f}} /$ $h_{\max }$ is close to 1 and the degree of work hardening is small. It should also be noted that when $h_{\mathrm{f}} / h_{\max }<0.7$, very little pileup is observed no matter what the work-hardening behavior of the material.

Recently, Walley discussed the possibility of defining an "absolute hardness" [15]. He pointed out that the major problem with all hardness testing methods is that they alter the material whose properties one is trying to measure. Walley reviewed many publications trying to define or measure an absolute value, and the only one he found to approach a solution resulted to be unpractical. Hardness tests are not designed to measure "absolute" properties, and practically, all efforts to eliminate the complicating variables and reduce them to a fundamental test have proved fruitless [15, 51].

Until recent years, it was common to speak in Europe about the calculation of the "Universal Hardness" (UH). For instance, the original draft of the ISO 14577 prepared in the year 2000 was using the term UH when referring to the hardness calculated by instrumented indentation tests. Another term used in the document was "Hardness under Test Force" referring to the way that hardness is calculated: the applied maximum force $L_{\max }$ divided by the contact area calculated at the maximum load $A_{\mathrm{s}}$ (see Fig. 9a for the comparison of $A_{\mathrm{c}}, A_{\mathrm{p}}, A_{\mathrm{pml}}$ and $A_{\mathrm{s}}$ ). According to Wilde et al. [52], many discussions in the ISO committee took place, as the denomination of "universal" could be confusing. Finally, it was decided to call it "Martens Hardness" (HM) in honor of the German Professor Adolf Martens, a leading researcher of steel characterization at the end of the nineteenth century. Adolf Martens was the first researcher to describe the steel structure that carries his name (martensitic) and also was the first to build an indentation machine at the macroscale measuring the penetration of the indenter at maximum load [52]. Martens Hardness is defined only for the symmetric pyramidal indenters Vickers and Berkovich. For a Vickers indenter with apex angle of $136^{\circ}$, the area $A_{\mathrm{s}}$ as function of the penetration $\mathrm{h}$ is given by:

$A_{\mathrm{s}}(h)=\frac{4 \sin (\alpha / 2)}{\cos ^{2}(\alpha / 2)} h^{2}=26.43 h^{2}$

while for a Berkovich indenter with apex angle $130.6^{\circ}, A_{\mathrm{s}}$ is:

$A_{\mathrm{s}}(h)=\frac{3 \sqrt{ } 3 \sin (\alpha / 2)}{\cos ^{2}(\alpha / 2)} h^{2}=26.44 h^{2}$

It is important to note the difference between $A_{\mathrm{s}}$ and $A_{\mathrm{p}}$ for the Berkovich indenter; Eq. (15) gives $A_{\mathrm{p}}(h)=24.56 h^{2}$. The Martens hardness for a Vickers indenter is then:

$\mathrm{HM}=\frac{L_{\max }}{A_{\mathrm{s}}(h)}=\frac{L_{\max }}{26.43 h^{2}}$

and for a Berkovich indenter, it will be given by:

$\mathrm{HM}=\frac{L_{\max }}{A_{\mathrm{s}}(h)}=\frac{L_{\max }}{26.44 h^{2}}$

Martens hardness values are determined from load and depth readings during the application of the test force, and the norm established that a penetration greater than $0.2 \mu \mathrm{m}$ depth is required [10]. The Martens hardness value is denoted by the symbol HM, followed by the test conditions that specify the indenter, the test force, the time of application of the test force, and the number of load steps applied if not a continuous application of force. For example, "HM (Berkovich) 0.5/20/30 = $6500 \mathrm{~N} / \mathrm{mm}^{2}$ ", represents a Martens hardness value of $6500 \mathrm{~N} / \mathrm{mm}^{2}$, determined with a test force of $0.5 \mathrm{~N}$, applied during $20 \mathrm{~s}$ in 30 steps. The main difference of HM with the standard Vickers hardness is that $A_{\mathrm{s}}$ take into consideration both elastic and plastic deformation because it is measured
Fig. 13 Schematics of a sink-in and $\mathbf{b}$ pileup around the indenter
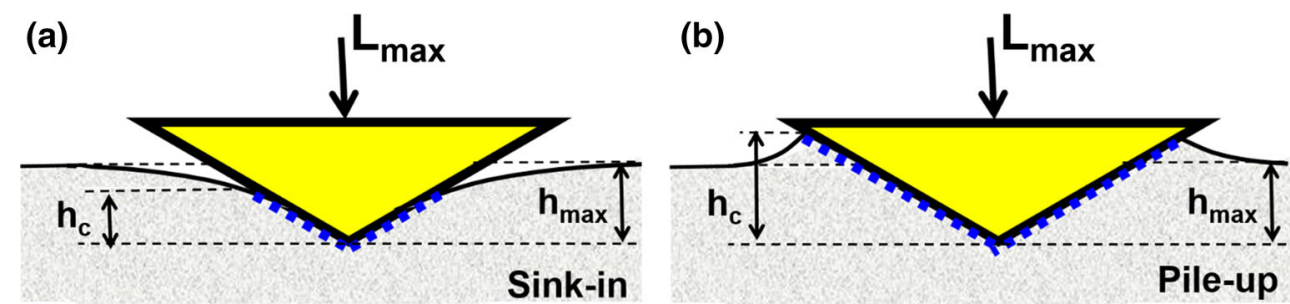
under the load, while $A_{\mathrm{p}}$ only is influenced by plastic deformation because it is measured after the indentation.

After our discussion regarding the ways to calculate hardness trough different kind of areas (contact area $A_{\mathrm{c}}$, projected area $A_{\mathrm{p}}$, projected area at maximum load $A_{\mathrm{pml}}$, contact area at maximum load $A_{\mathrm{s}}$ ) or penetrations depths, one question still remind: which one is more reasonable to define hardness? According to Tabor, macro- and microindentation hardness measurements in metals are essentially a measure of the elastic limit yield stress of the material. Therefore, he concluded that it is physically more meaningful to define hardness as a contact pressure using the projected area $A_{\mathrm{p}}$ [53]. It is a similar conclusion that was already reached by Meyer in 1908 when he proposed to change Brinell's hardness definition. However, as we have discussed in the previous paragraphs, if there are pileup effects due to the elasto-plastic nature of the material, the method of measuring the pressure through the projected area after unloading seems to fail. The more reasonable method, as it has been advised by the ISO committee, is measuring the Martens Hardness [52]. This method can already be used in nanoindentation experiments, and given the technological advances during the last decade in the design and construction of more precise hardness measurement equipment, it should not be a surprise to find in the near future durometers measuring the Martens Hardness also at macro- and microscale. The possibility to measure hardness with the same method at all scales will bring finally a solution to the quest of hardness comparison for different materials at macro-, micro-, and nanoscale.

\subsection{Practical Conversions Between Methods}

We have discussed in the previous section how hardness conversion between different methods cannot be made mathematically exact. Different loads, different shapes and materials of the indenters, different homogeneity of the sample at different scales, and the elastic properties of the material complicate the problem. Empirical equations have been deduced relating few specific materials [54].

At the macro- and microscale, there are conversion tables and charts that can be used to give approximate equivalent hardness values. These charts and scales are included in some standards where the values have been plotted and a conversion established. Two of such standards are BS ISO 18265 [55] and ASTM E140 [56]. The conversions for these standards are not exactly the same, but are similar, incorporating Vickers, Brinell, Rockwell (B and C) conversions for a limited number of material types. Some other hardness scales are included in the standards, but these are used less often.

Since the indentation methods are different, correlation of hardness readings taken with various methods should be taken just as an indication. ASTM E140-07 provides strong indications that hardness conversion is not as straightforward as one would like to believe:

... Conversion of hardness values should be used only when it is impossible to test the material under the conditions specified, and when conversion is made it should be done with discretion and under controlled conditions. Each type of hardness test is subject to certain errors, but if precautions are carefully observed, the reliability of hardness readings made on instruments of the indentation type will be found comparable. Differences in sensitivity within the range of a given hardness scale (for example, Rockwell B) may be greater than between two different scales or types of instruments. The conversion values, whether from the tables or calculated from the equations, are only approximate and may be inaccurate for specific application... [56].

In summary, hardness conversion is a very complex process. Conversion of readings from one scale to another or from one method to another should be done with precaution, only when it is absolutely necessary, and taken just as an indicative value.

Another problem arises when dealing with the hardness units. For instance, even if hardness is calculated as a force divided by an area, it is not correct to think of hardness as a pressure, because the pressure distribution is usually not uniform under the indenter, and the areas are considered in a different way according to the method: sometimes is the area where the force is applied, sometimes is the area after elastic recovery, and sometimes is the projected area. Furthermore, care should be taken when handling the units. For instance, it is true that a material of $30 \mathrm{HV}$ is harder than a material of $10 \mathrm{HV}$. However, $H=30 \mathrm{HV}$ does not mean that we have 30 hardness units of $1 \mathrm{HV}$, in a similar way that we express that in a mass of $25 \mathrm{~kg}$ we have 25 units of $1 \mathrm{~kg}$ mass. $\mathrm{HV}$ is not a unit of measurement, but the symbol (notation) of a conventional measurement method [51].

\subsection{Hardness Interpretation at Different Scales}

There are many papers claiming a "multiscale" hardness characterization of materials. However, a careful analysis of these papers shows that they are always limited to macro- and microscale, micro- and nanoscale, or macroand nanoscale indentation studies [57]. There are just very few studies comparing the indentation hardness of materials at the three scales. Grabco et al. [6] studied crystals with different types of bonds (ionic, ionic-covalent, covalent, covalent with some sharing Van der Waals bond, and metal bonds) in the form of single crystals and 
polycrystals. They used nanoindentation with a Berkovich indenter at loads in the range $0-0.2 \mathrm{~N}$, micro-indentation with Vickers diamond indenter in the range $0.01-2 \mathrm{~N}$, and macroindentation with a steel ball at loads $>10 \mathrm{~N}$. Rester et al. investigated the hardness of copper $\{111\}$ single crystals, with indentation depths ranging from 250 to $250 \mu \mathrm{m}$ [58]. They used cube-corner indenters mounted in three different indentation devices: a nanoindenter with loads in the range $0.5-10 \mathrm{mN}$, a microscale indenter with a load of $300 \mathrm{mN}$, and a macroscale indenter with loads of 10 and $100 \mathrm{~N}$. Studies comparing indentation with different geometries at nanoscale are also scarce. Rother et al. [59], Min et al. [60], and Sakharova et al. [61] studied the influence of the geometrical shape of Berkovich, Vickers, Knoop, and conical indenters on the hardness of bulk metals and composite materials.

The lack of multiscale publications can be related to same difficulties found when trying to make the comparison. The theory of conventional plasticity establishes that the mechanical properties of a material are independent of its length scale. Thus, the indentation hardness should be independent of the indentation size [62, 63]. However, real materials are usually far from the idealization [64].

\subsubsection{Multiscale Characterization in Polycrystalline Materials}

If we try to determine the hardness of homogeneous materials with dimensions of many decimeters (a relatively "infinite" material when comparing with the sizes of a macroscale indentation), we probably won't be able to measure different values of indentation hardness measured at the three scales. However, a difference will appear when we try to indent a polycrystalline material with inhomogeneous grains of microscale size diameters, like the one schematically shown in Fig. 14. In the case of a macroscale indentation, such a Vickers shown in Fig. 14a, the test creates a large indent size which will average the sample inhomogeneity, and a mean bulk hardness value is obtained. In the case of a microscale indentation, as the micro-Vickers test of Fig. 14b, a mean hardness will be measured but variations in small areas can also be assessed. Microscale indentations tests are very good to characterize segregation and banding, to identify constituents, and to characterize surface hardness/microstructure. In Fig. 14c, the nanoindentation (represented by triangular indents from a Berkovich or cube-corner indenter) can give hardness and elastic modulus variations in different grains (A, B) or the change of mechanical properties at grain boundaries (nanoindentation $\mathrm{C}$ ). Indentations at the nanoscale testing are good to analyze very thin materials like foils or coatings [65], or for measuring the surface of a part, small parts or small areas [66], measuring individual microstructures
[67], or measuring cross sections [68]. Thus, macro tests yield a material average hardness, while micro- and nanoscale tests indicate variations in different parts of the sample microstructure.

\subsubsection{Indentation Size Effects at Micro- and Nanoscale}

The Vickers indenter is designed to give geometrically similar indentations, so the hardness should be independent of the applied load and the indentation size. This fact results to be true for macroscale indentations. However, for microscale indentations (loads of less than 100 gf $\sim 0.98$ $\mathrm{N}$ ), it is well established that the hardness decreases or, more frequently, increases with the decrease in the applied load (Fig. 15). This effect is known as the "indentation size effect" (ISE) [39, 69].

There are many explanations found in the literature to describe the phenomena. Some authors relate ISE to a possible artifact caused by experimental errors originated from the small size of the indentation and lack of optical resolution, or due to surface preparation problems [70]. Other authors relate ISE to the intrinsic structural factors of the tested specimens like high elastic recoveries, pileup, lack of dislocations at small indentations, work hardening, and the presence of grain precipitates [71]. Nix and Gao established in 1998 a relation between the micro-indentation hardness $\mathrm{H}$ and the indentation depth $\mathrm{h}$ :

$$
\left(\frac{H}{H_{0}}\right)^{2}=1+\frac{h^{*}}{h}
$$

where $h^{*}$ is a characteristic length on the order of microns that depends on the properties of indented material and the indenter angle and $\mathrm{H}_{0}$ is the indentation hardness for a large indentation depth (e.g., $h \gg h^{*}$ ) [72]. This relation has been used by many authors to explain ISE at microscale indentations; however, the relation is not valid at nanoscale [71]. When the indentation depth $h<100 \mathrm{~nm}$, the nanoindentation hardness data are smaller than the predicted by Eq. (23). Two main factors for the discrepancy between this equation and nanoindentation hardness data have been discussed [71]:

1. The model used to deduce Eq. (23) holds only for "sharp" indenters, and the effect of indenter tip radius (typically around $50 \mathrm{~nm}$ in nanoindentation) has not been accounted for.

2. The model of Eq. (23) assumes that all dislocations are stored in a hemisphere of radius $a$, where $a$ is the contact radius of indentation. Such assumption is not valid in indentations at the nanoscale.

Recently, Gouldstone et al. [73] and Pharr et al. [74] have reviewed modeling and experimental data that have 


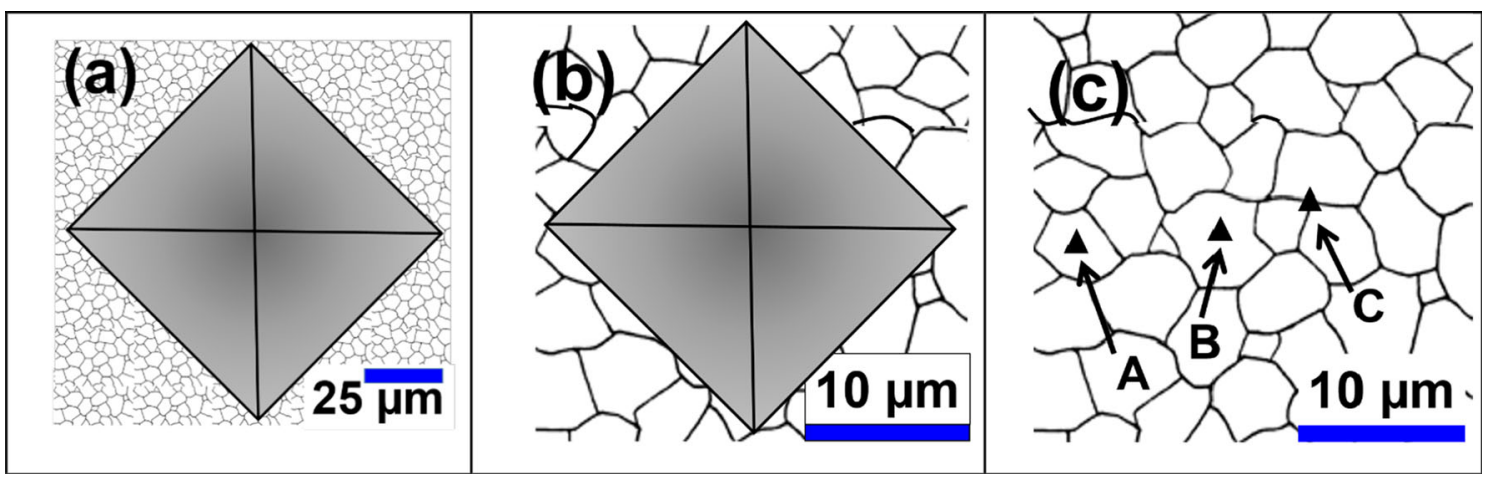

Fig. 14 Scheme of indentation hardness of a polycrystalline material at a macroscale; $\mathbf{b}$ microscale; and $\mathbf{c}$ nanoscale. Note that the scale in $\mathbf{a}$ is different to be able to visualize all the indented area

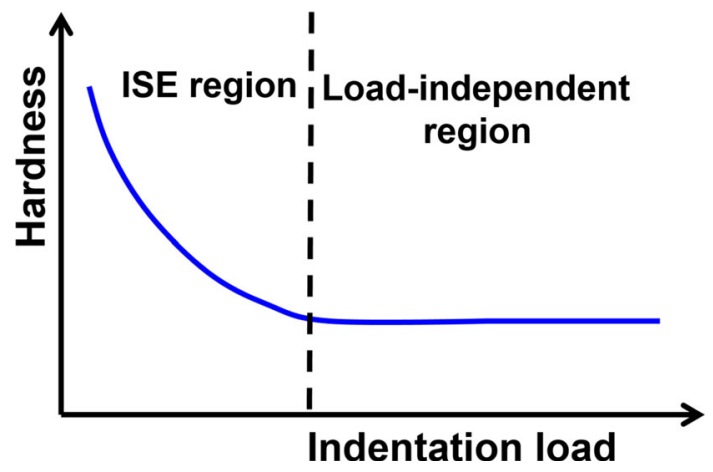

Fig. 15 Schematic diagram of indentation size effect (ISE)

been developed during the last two decades explaining ISE at nanoscale. They explain how there is a qualitative agreement of researchers that ISE appears when the dominant length scales of indentation deformation approach critical microstructural length scales of dislocation spacing. However, they also show that there is still no quantitative agreement about how to predict ISE, despite a large amount of modeling activity.

\subsubsection{Scale Effects on Coating/Substrate Systems}

When an indenter penetrates the surface of a film deposited onto a substrate, the mechanical response of the film will be influenced by the mechanical properties of the substrate, according to its penetration depth $\mathrm{h}$ and the film thickness $t$ (Fig. 16). As the depth of penetration $\mathrm{h}$ increases, more of the mechanical contribution will come from the substrate [75].

The first who tried to separate the contribution of the substrate from the total measured hardness at the microscale was Bückle [76], who proposed to model the hardness $H_{\mathrm{fs}}$ of the entire system (film + substrate) as a linear interpolation of the substrate hardness $H_{\mathrm{s}}$ and the film hardness $H_{\mathrm{f}}$ :

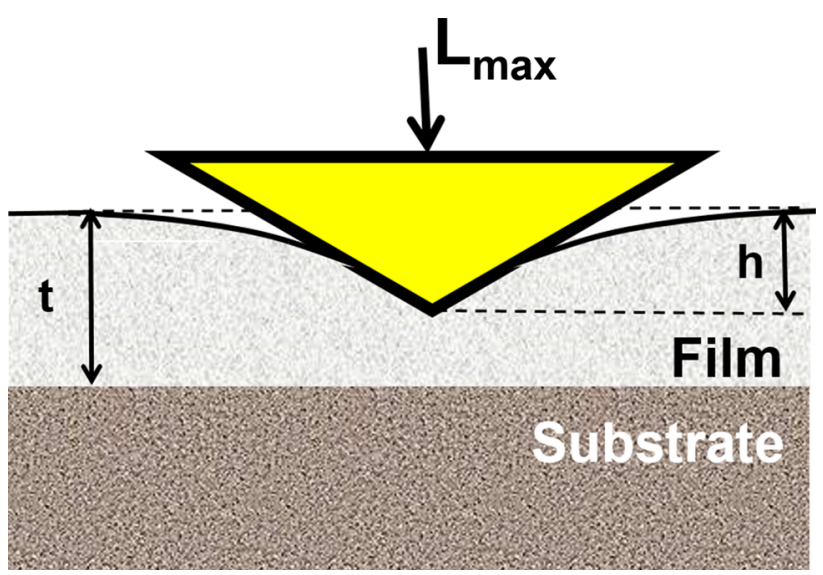

Fig. 16 Indentation of a film deposited onto a substrate

$H_{\mathrm{fs}}=\alpha H_{\mathrm{f}}+(1-\alpha) H_{\mathrm{s}}$

where $\alpha$ is a coefficient defined by:

$\alpha=\left[1-\frac{\exp (h-t)}{\Delta t}\right]^{-1}$

$t$ is the film thickness, $h$ is the depth of indentation, and $\Delta t$ is the dimension of the transition region; the meaning of $\Delta t$ was not really well described by Bückle. In his paper, Bückle also established a "rule of thumb" that recommends to indent no more than $1 / 10$ of the film thickness to avoid the influence from the substrate [76].

In the case of nanoscale indentation, the substrate effect on the determination of the film hardness is directly related to the expansion of the elastically and plastically deformed volume underneath the indenter during the loading phase [5]. Korsunsky et al. modeled $H_{\mathrm{fs}}$ as [77]:

$H_{\mathrm{fs}}=H_{\mathrm{s}}+\frac{H_{\mathrm{f}}-H_{\mathrm{s}}}{1+k\left(\frac{h_{\mathrm{c}}}{t}\right)^{2}}$

where $k$ is a fitting parameter and $h_{\mathrm{c}}$ is the contact depth determined according to the Oliver and Pharr method (Eq. 14). Other models for micro- and nanoscale 
indentations have also been reviewed by Korsunsky et al. [77], Fischer-Cripps [5], and Chen et al. [78].

Bückle's rule of the $10 \%$ film-thickness indentation depth limit has also been widely adopted in the case of indentations at nanoscale [79]. However, the rule is not valid all the time. Gamonpilas et al. [80] investigated the effect of the substrate on the nanoindentation behavior of coated systems using a combination of dimensional and finite element analyses. They found that the critical indentation depth to coating thickness ratio below which the substrate material has a negligible effect on the indentation response of the coated system depends on the yield strength $\sigma_{\mathrm{y}}$ and Young's modulus $E$ of the coating and substrate, i.e., $\sigma_{\mathrm{yc}} / \sigma_{\mathrm{ys}}$ and $E_{\mathrm{c}} / E_{\mathrm{s}}$. They found that Bückle rule is valid only when $\sigma_{\mathrm{yc}} / \sigma_{\mathrm{ys}}<10$. However, a maximum depth of $5 \%$ should be used to avoid any influence from the substrate when $\sigma_{\mathrm{yc}} / \sigma_{\mathrm{ys}}>10$ and $E_{\mathrm{c}} /$ $E_{\mathrm{s}}>0.1$. In a recent review, Chen et al. [78] discuss how Bückle's rule is not stringent enough for hard coatings on a very soft substrate, and inversely, the rule is too strict for soft coatings on a hard substrate. For instance, they show how the hardness of a very soft coating (hardness $<0.5 \mathrm{GPa}$ ) on a hard substrate (hardness $>10 \mathrm{GPa}$ ) will not be affected by substrate deformation even if the penetration of the indenter is more than $50 \%$ of film thickness.

The problem gets even more complex when the indentation is used to measure the hardness of multilayered thin films. This kind of films present a high degree of heterogeneity pertaining to soft/hard arrangement layers together with the large interface areas [81]. Analytical solutions are difficult to find, so in this case, the use of numerical finite element analyses is the only option to understand and solve the problem of substrate influence [82].

\section{Final Remarks}

A critical overview of indentation hardness measurements at different scales has been presented. We carefully discussed how hardness has been defined in each method: sometimes using the contact area, other times the projected area, and in other cases using the penetration depth of the indenter. These differences make very difficult and sometimes impossible the task to compare hardness measured by different methods and scales. The influence of elasticity and plasticity of the material was reviewed, and the impact on hardness calculation of pileup and sink-in of the material around the indenter was examined. Finally, the influence of grain size in polycrystalline materials, indentation size effects at micro- and nanoscale, and the effect of the substrate when calculating thin films hardness were also discussed. The paper provides to physicists, engineers, and metallurgists a better understanding of what hardness means and what indentation hardness measurements imply at different scales.

Acknowledgements The author gratefully acknowledges the financial support from the Swedish Government Strategic Research Area in Materials Science on Functional Materials at Linköping University (Faculty Grant SFO Mat LiU No 2009 00971).

Open Access This article is distributed under the terms of the Creative Commons Attribution 4.0 International License (http://crea tivecommons.org/licenses/by/4.0/), which permits unrestricted use, distribution, and reproduction in any medium, provided you give appropriate credit to the original author(s) and the source, provide a link to the Creative Commons license, and indicate if changes were made.

\section{References}

1. Mohs, F.: Versuch einer Elementar-Methode zur naturhistorischen Bestimmung und Erkennung der Foßilien, Volym 1. Camesina, Wien (1812)

2. Wade, W.: Hardness of metals. In: Reports on experiments on the strength and other properties of metals for cannon with a description of the machines for testing metals, and of the classification of cannon in service, pp. 259-275 and 313-314. Henry Carey Baird, Philadelphia (1856)

3. Tabor, D.: The Hardness of Metals. Clarendon Press, Oxford (1951)

4. Hutching, I.M.: The contributions of David Tabor to the science of indentation hardness. J. Mater. Res. 24(3), 581-589 (2009)

5. Fischer-Cripps, A.: Nanoindentation. Srpinger, New York (2011)

6. Grabco, D., Shikimaka, O., Harea, E.: Translation-rotation plasticity as basic mechanism of plastic deformation in macro-, micro- and nanoindentation processes. J. Phys. D Appl. Phys. 41, 074016 (2008)

7. Czichos, H., Saito, T., Smith, L.E.: Springer Handbook of Metrology and Testing. Springer Verlag, Berlin (2011)

8. Germak, A., Herrmann, K., Low, S.: Traceability in hardness measurements: from the definition to industry. Metrologia 47(2), S59-S66 (2010)

9. Herrmann, K.: Hardness Testing. Principles and Applications. ASM International, Materials Park (2011)

10. ISO 14577: Metallic Materials-Instrumented Indentation Test for Hardness and Materials Parameters. International Organization for Standardization, Geneva (2002)

11. Brinell, J.: Sätt att bestämma kroppars hårdhet jämte några tillämpningar of detsamma. Teknisk tidskrift 30, 69-87 (1900)

12. ASTM E10 - 15a: Standard Test Method for Brinell Hardness of Metallic Materials. ASTM International, West Conshohocken (2015)

13. ISO 6506-1-2014: Metallic Materials-Brinell Hardness TestPart 1: Test Method. International Organization for Standardization, Geneva (2014)

14. Meyer, E.: Untersuchungen über Härteprüfung und Härte Brinell Methoden, Zeitschrift. Des Vereines Deutscher Ingenieure 52, 645-654 (1908)

15. Walley, S.: Historical origins of indentation hardness testing. Mater. Sci. Technol. 28(9-10), 1028-1044 (2012)

16. Smith, R.L., Sandly, G.E.: An accurate method of determining the hardness of metals, with particular reference to those of a high degree of hardness. Proc. Inst. Mech. Eng. 102(1), 623-641 (1922)

17. ISO 6507-1-2005: Metallic Materials-Vickers Hardness TestPart 1: Test Method. International Organization for Standardization, Geneva (2005) 
18. ASTM E92-16: Standard Test Methods for Vickers Hardness and Knoop Hardness of Metallic Materials. ASTM International, West Conshohocken (2016)

19. Ludwik, P.: Die Kegelprobe-Ein neues Verfahren zur Härtebestimmung von Materialien. Springer, Berlin (1908)

20. Rockwell, H., Rockwell, S.: Hardness Tester. USA Patent 1294171, 15 July 1914

21. ISO 6508-1: Metallic Materials-Rockwell Hardness Test-Part 1: Test Method. International Organization for Standardization, Geneva (2016)

22. ASTM E18 - 16: Standard Test Methods for Rockwell Hardness of Metallic Materials. ASTM International, West Conshohocken (2016)

23. ISO 2039-2: Plastics-Determination of Hardness-Part 2: Rockwell Hardness. International Organization for Standardization, Geneva (1987)

24. Shore, A.: Apparatus for Measuring the Hardness of Materials. USA Patent 1770045,8 July 1930

25. ASTM D2240 - 15: Standard Test Method for Rubber PropertyDurometer Hardness. ASTM International, West Conshohocken (2015)

26. Coltro, L., Pitta, J., Madaleno, E.: Performance evaluation of new plasticizers for stretch PVC films. Polym. Testing 32(2), 272-278 (2013)

27. Barcol Impressor Company: The Barcol Impressor. http://www. barcol-impressor.com/. Accessed 17 Aug 2016

28. ASTM D2583 - 13a: Standard Test Method for Indentation Hardness of Rigid Plastics by Means of a Barcol Impressor. ASTM International, West Conshohocken (2013)

29. ISO 48: Rubber, Vulcanized or Thermoplastic-Determination of Hardness (Hardness Between 10 IRHD and 100 IRHD). International Organization for Standardization, Geneva (2010)

30. Morgans, R., Lackovic, S., Cobbold, P.: Understanding the IRHD and Shore Methods used in Rubber Hardness Testing. Paper Nr 131. Meeting of the Rubber Division, American Chemical Society, Orlando, Florida (1999)

31. ASTM D1415: Standard Test Method for Rubber Property-International Hardness. ASTM International, West Conshohocken (2012)

32. National Physics Laboratory (UK): Report for the Year 1932, pp. 180-181. National Physics Laboratory, Teddington (1993)

33. Lips, E., Sack, J.: A hardness tester for microscopical objects. Nature 138, 328-329 (1936)

34. ASTM E384 - 16: Standard Test Method for Microindentation Hardness of Materials. ASTM International, West Conshohocken (2016)

35. Knoop, F., Peters, C., Emerson, W.: A sensitive pyramidal-diamond tool for indentation measurements. J. Res. Natl. Bur. Stand. 23, 39-61 (1939)

36. ISO 2815: Paints and Varnishes-Buchholz Indentation Test. International Organization for Standardization, Geneva (2003)

37. Brown, R.: Physical Testing of Rubber. Springer, New York (2006)

38. Berkovich, E.: Three-faceted diamond pyramid fro microhardness testing. Ind. Diamond Rev. 11, 129-132 (1951)

39. Oliver, W., Pharr, G.: An improved technique for determining hardness and elastic modulus using load and displacement sensing indentation experiments. J. Mater. Res. 7(6), 1564-1583 (1992)

40. Oliver, W., Pharr, G.: Measurement of hardness and elastic modulus by instrumented indentation: advances in understanding and refinements to methodology. J. Mater. Res. 19(1), 3-20 (2004)

41. Pharr, G., Oliver, W., Brotzen, F.: On the generality of the relationship between contact stiffness, contact area, and elastic moduli during indentation. J. Mater. Res. 7, 613-617 (1992)
42. ASTM E2546: Standard Practice for Instrumented Indentation Testing. ASTM International, West Conshohocken (2015)

43. Broitman, E., Tengdelius, L., Hangen, U., Lu, J., Hultman, L., Högberg, H.: High-temperature nanoindentation of epitaxial ZrB2 thin films. Scripta Mater. 124, 117-120 (2016)

44. Soomro, M., Hussain, I., Bano, N., Broitman, E., Nur, O., Willander, M.: Nanoscale elastic modulus of single horizontal $\mathrm{ZnO}$ nanorod using nanoindentation experiment. Nanoscale Res. Lett. 7, 146-148 (2012)

45. Hussain, I., Khan, A., Nur, O., Willander, M., Broitman, E.: The effect of oxygen-plasma treatment on the mechanical and piezoelectrical properties of $\mathrm{ZnO}$ nanorods. Chem. Phys. Lett. 608, 235-238 (2014)

46. Broitman, E., Soomro, M., Lu, J., Willander, M., Hultman, H.: Nanoscale piezoelectric response of $\mathrm{ZnO}$ nanowires measured using a nanoindentation technique. Phys. Chem. Chem. Phys. 15(26), 11113-11118 (2013)

47. Broitman, E.: The nature of the frictional force at the macro-, micro-, and nano-scales. Friction 2, 40-46 (2014)

48. Tuck, J., Korsunsky, A., Bull, S.D.R.: On the application of the work-of-indentation approach to depth-sensing indentation experiments in coated systems. Surf. Coat. Technol. 137(2-3), 217-224 (2001)

49. Olsson, S., Broitman, E., Garbrecht, M., Birch, J., Hultman, L., Eriksson, F.: Mechanical and tribological properties of $\mathrm{AlCuFe}$ quasicrystal and $\mathrm{Al}(\mathrm{Si}) \mathrm{CuFe}$ approximant thin films. J. Mater. Res. 31, 232-240 (2016)

50. Norbury, A., Samuel, T.: The recovery and sinking-in or pilingup of material in the Brinell test and the effects of these factors on the correlation of the Brinell with certain other hardness tests. J. Iron Steel Inst. 117, 673-687 (1928)

51. Herrmann, K. (ed.): The fundamentals of hardness testing. In: Hardness Testing-Principles and Applications, pp. 1-23. ASM International, Materials Park (2011)

52. Wilde, H.-R., Wehrstdt, A.: Martens hardness HM-an international accepted designation for Hardness under test force. Materialswissenschaft und Werkstofftechnik 31, 937-940 (2000)

53. Tabor, D.: Indentation hardness and its measurement: some cautionary comments. In: Blau, P.J., Lawn, B.R. (eds.) Mincroindentation Techniques in Materials Science and Engineering-ASTM STP 889, pp. 129-159. American Society for Testing and Materials, Philadelphia (1989)

54. Yovanovich, M.: Micro and macro hardness measurements, correlations, and contact models. In: 44th AIAA Aerospace Sciences Meeting and Exhibit, Reno, Nevada (2006)

55. BS EN ISO 18265: Metallic Materials. Conversion of Hardness Values. British Standards Institution, London (2013)

56. ASTM E140-12be1: Standard Hardness Conversion Tables for Metals Relationship Among Brinell Hardness, Vickers Hardness, Rockwell Hardness, Superficial Hardness, Knoop Hardness, Scleroscope Hardness, and Leeb Hardness. ASTM International, West Conshohocken (2012)

57. Rivera-Tello, C.D., Broitman, E., Flores-Ruiz, F., Jiménez, O., Flores, F.: Mechanical properties and tribological behavior at micro and macro-scale of WC/WCN/W hierarchical multilayer coatings. Tribol. Int. 101, 194-203 (2016)

58. Rester, M., Motz, C., Pippan, R.: Indentation across size scalesa survey of indentation-induced plastic zones in copper 111 single crystals. Scripta Mater. 59, 742-745 (2008)

59. Rother, B., Steiner, A., Dietrich, D., Jehn, H., Haupt, J., Giessler, W.: Depth sensing indentation measurements with Vickers and Berkovich indenters. J. Mater. Res. 13(8), 2071-2076 (1998)

60. Min, L., Wei-min, L., Nai-gang, L., Ling-dong, W.: A numerical study of indentation using indenters of different geometries. J. Mater. Res. 19, 73-78 (2004) 
61. Sakharova, N., Fernandes, J., Antunes, J., Oliveira, M.: Comparison between Berkovich, Vickers and conical indentation tests: a three-dimensional numerical simulation study. Int. J. Solids Struct. 46(5), 1095-1104 (2009)

62. Ma, Z., Zhou, Y., Long, S., Lu, C.: On the intrinsic hardness of a metallic/film substrate system: indentation size and substrate effects. Int. J. Plast 34, 1-11 (2012)

63. Jones, R.: Deformation Theory of Plasticity. Bull Ridge, Blacksburg (2009)

64. Eriksson, R., Gupta, M., Broitman, E., Jonnalagadda, K.P., Nylén, P., Peng, R.L.: Stresses and cracking during chromiaspinel-NiO cluster formation in TBC systems. J. Therm. Spray Technol. 24, 1002-1014 (2015)

65. Broitman, E., Flores-Ruiz, F.J., Di Giulio, M., Gontad, F., Lorusso, A., Perrone, A.: Microstructural, nanomechanical and microtribological properties of $\mathrm{Pb}$ thin films prepared by pulsed laser deposition and thermal evaporation techniques. J. Vac. Sci. Technol., A 34, 021505 (2016)

66. Gård, A., Karlsson, P., Krakhmalev, P., Broitman, E.: Nano-scale friction and hardness of multi-phase powder metallurgy tool steels. Adv. Mater. Res. 1119, 70-74 (2015)

67. Khan, A., Hussain, M., Nur, O., Willander, M., Broitman, E.: Analysis of direct and converse piezoelectric responses from zinc oxide nanowires grown on a conductive fabric. Phys. Status Solidi (A) 212(3), 579-584 (2015)

68. Broitman, E., Becker, R. Dozaki, K., Hultman, L.: A novel oxide characterization method of nickel base alloy 600 used in nuclear plant reactors. In: Marquis, F.D.S. (eds.) PRICM 8: Advanced Materials and Processing, Chap. 415. Wiley, Hoboken (2013)

69. Iost, A., Bigot, R.: Indentation size effect: reality or artefact? J. Mater. Sci. 31, 3573-3577 (1996)

70. Vander Voort, G., Fowler, R.: Low-load Vickers microindentation. Adv. Mater. Processes 170(4), 28-33 (2012)

71. Huang, Y., Zhang, F., Hwang, K., Nix, W., Pharr, G., Feng, G.: A model of size effects in nano-indentation. J. Mech. Phys. Solids 54, 1668-1686 (2006)
72. Nix, W., Gao, H.: Indentation size effects in crystalline materials: a law for strain gradient plasticity. J. Mech. Solids 46, 411-425 (1998)

73. Gouldstone, A., Chollacoop, N., Dao, M., Li, J., Minor, A., Shen, Y.-L.: Indentation across size scales and disciplines: recent developments in experimentation and modeling. Acta Mater. 55, 4015-4039 (2007)

74. Pharr, G., Herbert, E., Gao, Y.: The indentation size effect: a critical examination of experimental observations and mechanistic interpretations. Annu. Rev. Mater. Res. 40, 271-292 (2010)

75. Alemón, B., Flores, M., Ramírez, W., Huegel, J., Broitman, E.: Tribocorrosion behavior and ions release of CoCrMo alloy coated with a TiAlVCN/CN ${ }_{x}$ multilayer in simulated body fluid plus bovine serum albumin. Tribol. Int. 81, 159-168 (2015)

76. Bückle, H.: Progress in micro-indentation hardness testing. Metall. Rev. 4, 49-100 (1959)

77. Korsunsky, A.M., McGurkm, M.R., Bull, S.J., Page, T.F.: On the hardness of coated systems. Surf. Coat. Technol. 99(1-2), 171-183 (1998)

78. Chen, J., Bull, S.: On the factors affecting the critical indenter penetration for measurement of coating hardness. Vacuum 83, 911-920 (2009)

79. Zocco, A., Perrone, A., Broitman, E., Czigány, Z., Hultman, L., Anderle, M., Laidani, N.: Mechanical and tribological properties of $\mathrm{CN}_{\mathrm{x}}$ films deposited by reactive pulsed laser ablation. Diam. Relat. Mater. 11, 103-109 (2002)

80. Gamonpilas, C., Busso, E.: On the effect of substrate properties on the indentation behaviour of coated system. Mater. Sci. Eng., A 380, 52-61 (2004)

81. Johansson, M.P., Hellgren, N., Berlind, T., Broitman, E., Hultman, L., Sundgren, J.-E.: Growth of CNx/BN: C multilayer films by magnetron sputtering. Thin Solid Films 360, 17-23 (2000)

82. Jamison, R., Shen, Y.-L.: Indentation and overall compression behavior of multilayered thin-film composites. J. Compos. Mater. 50(4), 507-521 (2016) 